\title{
BATS IN THE BISHOP'S STORTFORD AREA
}

\section{By J. Hayden and P. Kirkby (Bishop's Stortford College)}

(Reprinted, by permission, from The Starfish, No. 6, July, 1953, the journal of the Association of School Natural History Societies.)

In the winter of 1951-52 a few members of the Bishop's Stortford College Natural History Society decided to make a particular study of the bats frequenting the local countryside, both during the period of hibernation and in the active season.

Our first problem was that of finding an accessible colony where numbers of the animals could be captured and examined. This proved to be more difficult than had been expected; but a colony of wintering pipistrelles Pipistrellus pipistrellus, was eventually located behind three large honours boards on the wall of a staircase within the College precincts. Although extrication of the bats was often difficult, sufficient were obtained for certain kinds of work to be carried out successfully. During this first winter the observations were confined to three aspects- (i) biometrical measurements, (ii) feeding habits and (iii) homing experiments.

All the pipistrelles handled were measured, weighed and ringed. Measurements were taken of the length of the forearm, the third digit, tail and wing-span. Ringing was eventually carried out by fixing to the forearm numbered aluminium bands made for the Society to the specifications of Mr. John Hooper, the spelæologist. These have proved to be wholly satisfactory and it is hoped eventually to build up a picture of the animals' movements and expectation of life with their aid. Several authorities have suggested that bats possess some sort of "homing" instinct, and we have begun to investigate the possibility of this by releasing animals at distances of up to 14 miles from the colony. So far, only one return to the roost has been detected : it was that of a pipistrelle released on a mild night in winter at Sawbridgeworth, 4.7 miles distant.

Information about the diet of the pipistrelle was gained by analysis of their dung and the selection of food by captive specimens. Apparently the pipistrelles return to the roost with the larger and more powerful insects which they have taken on the wing and kill them in the shelter of the boards. In the process of mastication, recognizable portions of the chitinous exo-skeleton fall away and become intermingled with the finer material constituting the dung. These pieces can be separated 
by shaking the dung with water and, by this method, remains of the following insects have been identified.

\section{LEPIDOPTERA.}

Sphecia bembeciformis (lunar hornet-moth), Dipsosphecia scopigera (six-belted clearwing), Euproctis similis (yellow-tail moth), and many essentially nocturnal species.

Drptera.

Eristalis tenax (drone-fly), Fannia fuscula (lesser house-fly), Limnophila punctata, Bombylius major (bee-fly), Nephrotoma quadrifaria, Calliphora vomitoria (bluebottle), Tipulida-five species, and immense numbers of gnats.

Neuroptera.

Chrysopidae (lacewings).

Coleoptera.

Dorcus parallelopepedus (lesser stag-beetle), Aphodius finetarius, a weevil, and many smaller beetles.

DERMA PTERA.

Forficula auricularia (common earwig).

Such a list cannot be held to present a general picture of the normal diet, mainly because only the exceptionally large insects have received emphasis. The inclusion of forms which habitually fly only in strong sunlight are particularly interesting and may represent stragglers picked up by the first bats to emergea case of the early bird catching the late worm.

In the experiments conducted with specimens in captivity with a view to finding what the animals will accept as opposed to what they normally obtain, insects proffered included wellknown examples of the so-called Batesian and Mullerian mimicry. It was interesting to observe that neither form of mimery deceived the pipistrelles : every type of hover-fly, for example, was devoured without hesitation. However, some brightly coloured insects were rejected-peacock butterfly and garden tiger-moth, for example-so that some support is lent to the theory of "warning coloration".

Statistics obtained from biometrical data indicate that, in the pipistrelle, adult females tend, on the average, to be slightly larger but lighter in weight than the males.

In the spring of $\mathbf{1 9 5 2}$ it became evident that the honours boards provided shelter only for a winter roost of pipistrelles. As soon as the mild weather developed the site was completely 
abandoned and the bats dispersed to new roosts which have never been located. The winter roost varied in size from week to weck, even in the depth of the cold season, large numbers assembling after a few days of intense cold and many dispersing at the onset even of a brief spell of warmer conditions. Up to the present time no reliable estimate of the actual population has been obtained, so that quantitative measurements of the effects of climatic conditions have yet to be decided.

After the disintegration of the colony we turned our attention to the observations of the various local species in the field. It quickly became evident that the vespertilionid bats were well represented around Stortford and by the end of the summer six species had been identified. These are :-

Pipistrellus pipistrellus (pipistrelle), Nyctalus noctula (noctule), Nyctalus leisleri (Leisler's bat), ${ }^{1}$ Myotis daubentoni (Daubenton's bat), Myotis mystacinus (whiskered bat), Plecotus auritus (longeared bat).

of these the pipistrelle is universally distributed, frequenting the built-up areas and open country alike. The noctule also is common but more restricted in dispersal, apparently occurring in definite colonies. Daubenton's bat has appeared on all the stretches of the River Stort, sometimes in considerable numbers ; and Leisler's bat has been recorded twice, once at Eastwick and once when a young male was taken in a College dormitory. The whiskered bat is regarded as rare in East Anglia, but a single specimen was captured some 8 miles from Stortford and handed to a member of the Natural History Society. The long-eared bat has been noticed in several places near the town but seems to be scarce within Bishop's Stortford itself.

The claim has frequently been made that the smaller bats hunt their prey over a defined "beat", and this has been wholly borne out by our observations. There is apparently a correlation between the amount of insect-food available in an area and the form of the " beat" in the pipistrelle. Should food be relatively scarce the bats seem to keep to a fixed "beat" with greater regularity. In the spring we have noticed a certain amount of aerial quarrelling between bats and we suggest that if food be abundant pipistrelles wander from their restricted course but do not squabble. Many pipistrelle "beats" have been plotted and

1 The record of Leisler's bat is the first for Hertfordshire. Measurements from a specimen caught in the College on 4th October, 1952, are : forearm $42.0 \mathrm{~mm}$., third digit $72 \mathrm{~mm}$., tail $34 \mathrm{~mm}$., wing-span $290 \mathrm{~mm}$., weight $12 \cdot 75 \mathrm{gm}$. The identification has been confirmed from these measurements and from description of the colour by Mr. Michael Blackmore.-ED. 
their comparative lengths seem to be related and adjusted to the insect density.

Daubenton's bat has invariably been encountered over water, often hying very cluse to the surface. It appears always to pass under the arches of bridges rather than quit the vicinity of the water, and it is noteworthy as one of the latest bats to emerge each evening. The noctule hunts in societies and seems to prefer the locality of elms : flight is of short duration in the evening and begins early, about one hour before sundown. Observation of the duration and general pattern of the flight of the other vespertilionids has yet to be made by us, but we have recorded the flight of the pipistrelle as commencing on occasions some two hours before sunset and to last until 1.30 a.m. The same bat has been known to fly at 4 o'clock on other mornings.

When the average height of pipistrelles flying over a busy main road in Hertfordshire was compared with the altitude of pipistrelle " beats" over fields and timbered ground, it was clear that the bats hunting over the road were moving at the higher level. Possibly this is because they have become accustomed to the passage of double-decker buses and heavy pantechnicons, and have adopted the more elevated position in avoiding them. It may be that the insect prey is deflected upwards either by convection-currents from the tarred surface or by traffic. Whatever the explanation, the fact is well shown by graphical data. The noctule and Leisler's bat are very similar and, in the field, differ in size only. For this reason the two are often confused and, as both species occur in the district, field observations on them have been grouped together as referring to the genus Nyctalus. A graphical representation of the altitudes of their flights reveals two peaks : the lower is possibly Leisler's and the higher that of the noctule.

A reference has been made earlier to the use of captive pipistrelles in experimental work. Several members of the Society have kept tame pipistrelles with varying degrees of success. It has been noticed that pipistrelles taken into captivity soon undergo a marked darkening of the tongue, soft palate, and the bases of the incisors and premolars, even though they are fed exclusively on insect food. Evidently there is some deficiency in the diet, possibly a vitamin since the original colour has rapidly been restored by including minute quantities of raw liver in the diet. A similar result has been obtained by feeding an affected animal on numbers of greenbottle flies. 